\title{
Violência e juventudes: reflexões sobre homicídios de jovens no Espírito Santo
}

\author{
Violence and youth: reflections on youth homicides in Espírito Santo
}

Raysa Gloria dos Santos Raymundo CALAZANS*

https://orcid.org/oooo-0002-7861-4729

Silvia Moreira TRUGILHO***

https://orcid.org/000o-0002-6248-6056

\section{Luciana Carrupt Machado SOGAME ***}

https://orcid.org/oooo-0oo1-6913-5497

\begin{abstract}
Resumo: O artigo aborda a violência cometida contra as juventudes, a partir da consideração dos homicídios de jovens, tendo por objetivo desenvolver uma análise crítica reflexiva sobre a violência letal que incide sobre os jovens no Brasil e, em especial, no estado do Espírito Santo. Resulta de uma pesquisa social aplicada de abordagem quanti-qualitativa, documental, fundamentada no referencial teóricometodológico do materialismo histórico dialético. Utilizou como fontes os documentos denominados Mapa da Violência e Atlas da Violência, além de documentos de produção do Instituto Jones dos Santos Neves, bem como fontes de literatura científica disponibilizada nas bases de dados indexadas na área de ciências sociais aplicadas. A conclusão aponta para a realidade de desproteção social das juventudes no estado do Espírito Santo e o registro, por décadas, dos maiores índices de homicídios de jovens no País especialmente os do sexo masculino, negros, pobres, em muitos casos envolvidos em atividades relacionadas ao tráfico de drogas.
\end{abstract}

Palavras-chave: Juventudes. Violência. Homicídio. Juvenicídio.

Abstract: This article addresses violence committed against youths, particularly the homicides of young people, with the objective of studying a reflexive critical analysis on lethal violence that affects young people in Brazil and, especially, in the state of Espírito Santo. It results from applied social research with a quantitative-qualitative documentary approach, based on the theoretical-methodological framework of dialectical historical material. It uses a document called the Map of Violence and Atlas of Violence, documents produced by the Jones dos Santos Neves Institute and scientific literature available in databases in the area of applied social sciences as its sources. The conclusion points to the reality of social

\footnotetext{
* Advogada. Mestre em Políticas Públicas e Desenvolvimento Local pela Escola Superior de Ciências da Santa Casa de Misericórdia de Vitória (EMESCAM). Avenida Nossa Senhora da Penha, 2190, Santa Luíza, Vitória (ES), CEP: 29045-402. E-mail: raysa_gloria@hotmail.com.

** Assistente Social. Doutora em Educação. Docente do Programa de Políticas Públicas e Desenvolvimento Local da Escola Superior de Ciências da Santa Casa de Misericórdia de Vitória (EMESCAM). Avenida Nossa Senhora da Penha, 2190, Santa Luíza, Vitória (ES), CEP: 29045-402. Email: silvia.trugilho@emescam.br.

${ }^{* * *}$ Fisioterapeuta. Doutora em Ciências da Saúde. Docente do Programa de Políticas Públicas e Desenvolvimento Local da Escola Superior de Ciências da Santa Casa de Misericórdia de Vitória (EMESCAM). Avenida Nossa Senhora da Penha, 2190, Santa Luíza, Vitória (ES), CEP: 29045-402. Email: luciana.sogame@emescam.br.
} copiar e redistribuir o material em qualquer suporte ou formato, bem como adaptar, transformar e criar a partir deste material para qualquer fim, mesmo que comercial. O licenciante não pode revogar estes direitos desde que você respeite os termos da licença. 
deprotection of young people in the state of Espírito Santo which has, for decades, recorded the highest homicide rates of young people in the country, especially of poor, black men, in many cases involved in activities related to drug trafficking.

Keywords: Youth. Violence. Homicide. Adolescent homicide.

Submetido em: 30/10/2019. Revisado em: 26/3/2020. Aceito em: 16/4/2020.

\section{Introdução}

$\mathrm{O}$ texto que aqui se delineia versa sobre a violência na forma de homicídios de jovens no estado do Espírito Santo. Para a abordagem do homicídio de jovens como expressão da violência, tomamos por referência a realidade contundente expressa pelos elevados índices de violência letal cometida contra os jovens, associada à compreensão teórica de que a violência se constitui como parte de uma totalidade social, resultante de um conjunto de determinantes inseridos nos marcos das relações de produção e na organização estrutural da sociedade, especialmente marcadas nas condições desiguais de poder e riqueza. A concepção de jovens, no texto segue o disposto no Estatuto da Juventude - Lei no 12.852/2013, compreendendo pessoas na faixa etária de quinze a vinte e nove anos (BRASIL, 2013).

Transformações societárias contemporâneas, decorrentes do processo histórico de expansão do capital e sua mundialização, revelam novas configurações de mundo e sociabilidade que determinam múltiplas formas de violência presentes no cotidiano das relações sociais, na totalidade dos espaços constitutivos da vida social, como aponta Silva (2015). Para Netto (2012), o capitalismo em seu atual estágio de organização e produção é destrutivo, cuja destrutividade, expressa em forma de barbárie, inclui o fenômeno do belicismo.

O capitalismo não se mostra capaz de suprimir as violências que acompanham o desenvolvimento da humanidade. Pelo contrário, atua como remodelador da violência em cada fase do seu desenvolvimento, tendo em vista que sua força produtiva se constitui, segundo Ianni (2003), de força de trabalho, capital, tecnologia, planejamento, divisão do trabalho social e violência, ao mesmo tempo em que se desenvolvem as relações de produção.

As transformações sociais provocadas pelo capitalismo globalizado e neoliberal reverberam nas formas de sociabilidade contribuindo para a materialização da violência em suas múltiplas formas, como se verifica no Brasil, e tem se manifestado por meio do extermínio da vida dos nossos jovens. Essa realidade expressa em elevado número de jovens vítimas de lesões fatais é denunciada por Freitas, Silva, Brasil, Bastos e Fernandes (2017).

Somente no ano de 2016 foram registrados pelo Sistema de Informação sobre Mortalidade (SIM), do Ministério da Saúde, 62.517 homicídios no Brasil, correspondendo a uma taxa de 30,3 mortes para cada 100 mil habitantes, 50,3\% destes óbitos são de jovens (15 a 29 anos) do sexo masculino (INSTITUTO DE PESQUISA ECONÔMICA APLICADA, 2018). Para Silva e Lopes (2009) a vulnerabilidade dos jovens pobres, negros e do sexo masculino é inegável diante do que apontam as estatísticas. 
É reconhecido que a maior parte dos jovens mortos são moradores de áreas periféricas, pouco assistidas pelo poder público, que vivem em condições de precariedade em quase todos os aspectos e sem expectativas quanto ao próprio futuro. Esses indivíduos estão entre as maiores vítimas de homicídio no Brasil, especialmente aqueles residentes nas áreas de periferia urbana, evidenciando que essas mortes possuem geografia e endereço determinado (BRASIL, 2017).

A partir das considerações até aqui tecidas, objetiva-se desenvolver uma análise crítica e reflexiva sobre a violência letal que incide sobre os jovens na realidade brasileira contemporânea, tomando como referência a situação de homicídios de jovens no Espírito Santo. Tal análise se faz apoiada em um referencial teórico crítico, presente no campo das ciências sociais. Sua produção resulta da realização de uma pesquisa social aplicada de abordagem quanti-qualitativa, documental, fundamentada no referencial teórico-metodológico do materialismo histórico dialético. Utilizou-se como fontes os documentos denominados Mapa da Violência e Atlas da Violência, além de trabalhos de produção do Instituto Jones dos Santos Neves. A adoção da pesquisa documental de abordagem quanti-qualitativa foi pautada na compreensão de que a junção destas duas abordagens em um enfoque misto possibilita uma análise tanto estrutural quanto processual do fenômeno social em estudo.

O procedimento de coleta de dados contemplou a realização de um levantamento de dados documentais, utilizando como fontes documentos de domínio público, a saber: Mapas da Violência, de produção do pesquisador Júlio Jacobo Waiselfisz; Atlas da Violência e Anuários de Segurança Pública, publicados pelo Instituto de Pesquisa Econômica Aplicada (IPEA); manuais sobre violência, de confecção do Núcleo de Estudos da Violência (NEV), da Universidade de São Paulo; relatórios sobre violência, homicídios e juventudes, das Organizações Unidas (ONU), Organização Mundial da Saúde (OMS) e Organização das Nações Unidas para a Educação, a Ciência e a Cultura (UNESCO); Cadernos da Juventude e Boletins de Informações Criminais confeccionados pelo Instituto Jones dos Santos Neves (IJSN) e; estudos e projetos sobre juventudes, promovidos pelo Governo Federal e pelo Governo do Estado do Espírito Santo. Todos dispostos em bancos de dados de sítios eletrônicos públicos, o que oportunizou a consolidação de raciocínios embasados, seguindo a preceitos éticos.

O tratamento analítico dos dados se deu pelo método de análise de conteúdo, a partir da estratégia de análise de dimensão ampliada e inter-relacional (PRATES, 2016), o qual compreende a articulação entre os dados quantitativos e qualitativos. Assim, procedeuse à análise interpretativa e explicativa dos conteúdos destacados dos documentos, por meio da mediação entre conteúdo, interpretação inferencial e o referencial teórico adotado a partir de levantamento bibliográfico realizado em bases de dados indexadas na área de ciências sociais aplicadas.

\section{Violência, sociabilidade e juventude}

Os novos padrões de sociabilidade decorrentes da expansão do capital em âmbito mundial apresentam múltiplas formas de expressão, dentre as quais se destaca a violência dirigida aos jovens - fenômeno bastante presente na realidade brasileira e que 
nos exige um olhar atento para a compreensão dos seus contornos. Scherer (2018a) ressalta que "[...] as juventudes se constituem como um dos segmentos sociais mais afetados pela dinâmica do capital na atual conjuntura” (SCHERER, 2018a, p. 51).

Para Ianni (2002), na realidade do mundo contemporâneo a violência está evidente e latente, mas também difusa, afetando indivíduos, grupos sociais e coletividades e, como fenômeno histórico, contempla formas de sociabilidade e jogos de poder. Enraizada no tecido social, a violência, enquanto fenômeno inscrito na ordem da dinâmica societária e sua estrutura, em sua característica discreta, constitui-se, na concepção de Scherer, Nunes e Santos (2017) como um pano de fundo para todas as formas de violência ao passo que sustenta valores e normas que propulsionam o capitalismo e naturalizam as desigualdades sociais e a pobreza.

Na realidade brasileira, segundo Costa (1999), a violência na sua expressão urbana ganhou destaque na mídia na década de 1970, quando os índices de criminalidade e de homicídios, principalmente nas cidades do Rio de Janeiro e São Paulo, atingiram números até então inéditos. "Foi nesta época também que o controle territorial por grupos armados passou a compor o cotidiano das favelas, periferias e espaços populares brasileiros" (RODRIGUES, 2014, p. 13).

Costa (1999) atribui este fenômeno aos perversos efeitos da extrema mercantilização capitalista, que atua aniquilando valores e normas incompatíveis com a ideologia do lucro fácil e da imediata satisfação provocada pelo desejo de consumir. O capitalismo ao reproduzir a questão social é enxergado por Oliven (2010) como propulsor da violência, pois a insegurança experimentada pelas populações que vivem nas cidades e agora até no interior reflete o modelo de capitalismo selvagem, sobre o qual se desenvolveu o Estado brasileiro, que excede nas desigualdades sociais e no arbítrio.

Nas cidades brasileiras as violências se manifestam, segundo Weyrauch (2011), em razão da privação da população quanto ao exercício dos direitos sociais e da própria sobrevivência. Além disso, a autora afirma que em países com grande concentração de renda (como no caso do Brasil) este fenômeno é alimentado política e economicamente pelo capitalismo globalizado.

No Brasil, a noção de sociabilidade tem contribuído no trabalho daqueles que têm procurado compreender o fenômeno da violência não apenas em um patamar quantitativo, mas também qualitativamente, isto é, enquanto representação social e significado para o próprio agente promotor da violência (FRANÇA, 2019). Os padrões atuais de sociabilidade parecem afetar sobretudo as juventudes, expostas às manifestações civilizatórias do capital na contemporaneidade.

A juventude passou a compor um cenário de preocupação social quando problemas relacionados à sua entrada no mundo do trabalho, a inserção social decorrente da exclusão provocada pela crise por falta de empregos e o aumento da violência provocaram dificuldades em se construir um projeto de vida (FREITAS, 2005). 
Existem inúmeras produções científicas que têm empenhado esforços na análise da juventude, todavia, muitas delas se equivocam ao fazer esta análise "[...] por meio da reprodução de tendências múltiplas que podem levar a concepções homogeneizadoras, sanatizadoras ou adultocêntricas, ocultando pluralidades e singularidades desse segmento social" (SCHERER, 2018a, p. 49).

Ao se referir à juventude, Scherer (2014) afirma que esta fase não comporta homogeneidade e por isso precisa ser analisada na consideração de sua heterogeneidade. Assim, a utilização do termo juventudes, no plural, é para o autor o mais adequado para a abordagem de juventude. Isso significa que a juventude, embora possa exibir elementos comuns, não se apresenta de modo unívoco e homogêneo, haja vista que carrega em si a pluralidade e a diversidade. Essa pluralidade aqui referida está relacionada a elementos de diferenciação na situação de juventude que se manifesta de modo desigual segundo fatores como classe social, raça/cor, gênero, território, nas distintas realidades econômicas, sociais e culturais vivenciadas por esse grupo social compondo um mosaico de modos distintos de ser jovem, na diversidade de interesses, características, identidades e atribuições sociais.

Alinhados a este pensamento estão Esteves e Abramovay (2007) para quem "[...] não existe somente um tipo de juventude, mas grupos juvenis que constituem um conjunto heterogêneo, com diferentes parcelas de oportunidades, dificuldades, facilidades e poder nas sociedades" (ESTEVES; ABRAMOVAY, 2007, p. 21).

Não se pode compreender as juventudes de forma desarticulada da totalidade social sem incidir no risco de reproduzir tendências pós-modernas de fragmentação do real, que permitem apenas uma visão superficial da realidade em que vivem (SCHERER, 2018a). Logo, para entender a realidade da categoria juvenil no Brasil um perpasse sobre fatores que compõem e formam esta sociedade precisam ser analisados.

O desenvolvimento histórico brasileiro, na análise de Marini (2000), revela a junção da super exploração e da concentração de riquezas típica do capitalismo periférico latinoamericano. Há uma relação histórica de subordinação e dependência das nações da América Latina às economias dos países centrais do capitalismo, o que explica a impossibilidade dessas nações se desenvolverem da mesma forma que aquelas consideradas avançadas. Na visão do autor, por estar nesse contexto, o desenvolvimento socioeconômico do capitalismo brasileiro pode ser compreendido por meio da Teoria Marxista da Dependência que explica a sua natureza sui generis quando observado nacional e internacionalmente.

Neste caso, o processo de desenvolvimento econômico brasileiro, com suas desigualdades decorrentes é enxergado como um produto do capitalismo mundial. Essa dinâmica metabólica provoca, inevitavelmente, um forte impacto nas juventudes brasileiras que sofrem com a precarização do mundo do trabalho, com as dificuldades de acesso ao ensino, com a pobreza e com as violências decorrentes de toda esta conjuntura (SCHERER; GERSHENSON, 2016). 
Ruggieri Neto (2012) afirma que "[...] partindo de um olhar histórico, verifica-se uma evolução do tratamento político da juventude, tanto em termos qualitativos quanto quantitativos" (RUGGIERI NETO, 2012, p. 129). Entretanto, Scherer e Gershenson (2016) chamam atenção para o fato de que, apesar do registro de alguns avanços históricos, ainda prevalece uma lógica de (des)proteção, na medida em que as ações de proteção social para os jovens se dão de modo fragmentado, pontual, precarizado, na esteira da lógica do capital que na dinâmica da sociedade brasileira apresenta como efeitos a violação de direitos e o acirramento das manifestações da questão social vivenciado cotidianamente pelas juventudes.

O momento atual de intensa crise econômica, social e política, em que o conservadorismo e neoliberalismo abalam as bases do Estado democrático de direito brasileiro a fim de beneficiar a sociabilidade do capital radicalizando a questão social, resulta em consequências nefastas para as juventudes (YAZBEK; DEGENSZAJN; PAZ, 2019), haja vista que representa um enfraquecimento das poucas e recentes conquistas em políticas públicas voltadas para este segmento. O segmento jovem se vê refém da dinâmica atual de reprodução ampliada do capital que acarreta perdas de direitos, concomitante aos processos de precarização do trabalho e das políticas públicas.

As juventudes no Brasil têm enfrentado dois grandes desafios nas últimas décadas, segundo afirmam Cara e Gauto (2007). Um deles diz respeito ao acesso ao mundo do trabalho que apesar de atingir diversos segmentos da sociedade acaba sendo mais rigoroso com esta categoria. Outro é a violência, presente majoritariamente entre os jovens. Portanto, "[...] se o ingresso no mercado de trabalho se configurou como uma preocupação clássica dos jovens, as questões relativas à violência constituem suas preocupações contemporâneas" (CARA; GAUTO, 2007, p. 177). A vulnerabilidade desta categoria se evidencia através dos índices que apontam que tão grande quanto as taxas de desemprego é a violência que os atinge, com destaque para os homicídios.

\section{O juvenicídio no caso brasileiro}

De acordo com a Tábua completa de mortalidade para o Brasil referente ao ano de 2017, a expectativa de vida ao nascer, para este ano, foi de 76 anos (INSTITUTO BRASILEIRO DE GEOGRAFIA E ESTATÍSTICA, 2018). Entretanto, considerando a morte em jovens presente na realidade brasileira, muitos não alcançarão esta idade. Implícita nesta probabilidade estão as fases pelas quais esses seres humanos irão passar e consequentemente os desafios que terão que ser superados em cada uma delas para que não deixem de existir prematuramente e a expectativa de duração dessas vidas se concretize.

Dentre tais desafios estão os homicídios, pois conforme se verifica no Atlas da Violência publicado pelo Instituto de Pesquisa Econômica Aplicada (IPEA), o ano de 2015 apresentou um total de 59.08o pessoas vítimas de homicídio no Brasil o que equivale a 28,9 mortes para cada 100 mil habitantes (INSTITUTO DE PESQUISA ECONÔMICA APLICADA, 2017). 
E, ainda segundo o IPEA (2017), existe uma concentração de 47,8\% do total das mortes nas idades de 15 a 29 anos do sexo masculino, este indicador é ainda mais emblemático quando consideramos os homens de 15 a 19 anos, atingindo a marca dos 53,8\%. Os jovens, sobretudo, os do sexo masculino são as principais vítimas de homicídio e, apesar de este fenômeno apontar uma violência social, tal tema não tem sido tratado com prioridade pela sociedade e nem pelo Estado brasileiro (COSTA; SCHENKER; NJAINE; SOUZA, 2017).

Pelo contrário, a morte de jovens negros, pobres e habitantes das margens urbanas tem sido comemorada na realidade brasileira contemporânea em razão de um pensamento coletivo reproduzido pelo Estado e pela mídia e endossado pela população de que essas pessoas devem morrer por serem a objetificação do mal, contra o qual se deve lutar em defesa da ordem e da sociedade (BARROS; BENICIO; SILVA; LEONARDO; TORRES, 2017).

Para designar o fenômeno do exponencial número de mortes de jovens por meio de homicídios foi cunhado pelo professor e pesquisador mexicano Valenzuela (2016, p. 231) o termo juvenicídio que de acordo com ele representa um "[...] processo que implica uma condição persistente que custa a vida de dezenas de milhares de jovens do México, centenas de milhares na América Latina e se estende por toda a Europa" (VALENZUELA, 2016, p. 231, tradução nossa).

Para Valenzuela (2016), o juvenicídio se configura como um processo constituído por diversos fatores que incluem a precarização da vida dos jovens, a pobreza, a desigualdade, a estigmatização, a ampliação de sua vulnerabilidade econômica e social e a diminuição das opções disponíveis que os possibilitem desenvolver seus projetos de vida. Esse processo, que tem seu eixo centrado na estratificação social, resulta em um dinâmica de criminalização e morte de jovens.

O termo juvenicídio "[...] ilustra a condição de mortalidade juvenil, provocada pela dinâmica societária contemporânea que desestabiliza vidas de jovens em todo globo, especialmente em países de desenvolvimento capitalista tardio e periférico [...]" (SCHERER; NUNES, 2018, p. 11-12), como é o caso do Brasil.

Na concepção de Melo, Silva e Garcia (2017), no que tange à particularidade brasileira, estudos têm demonstrado que além de questões individuais, fatores como desemprego, baixa escolaridade, pobreza e desigualdades sociais estão diretamente ligados a esta violência letal. São mortes predominantemente de homens negros que ocorrem em espaços públicos, relacionadas à criminalidade e promovida igualmente por agentes do sexo masculino segundo informam Routti, Massa e Peres (2011).

Um recorte importante no caso dos homicídios que ocorrem no Brasil é étnico-racial. Jovens do sexo masculino pretos compõem a maior parte dos mortos, seguidos por pardos e brancos. O principal gestor desta dinâmica homicida que mata jovens do sexo masculino, pobres e negros é o tráfico de drogas. Estudos demonstram que "[...] o crescimento dos óbitos por homicídios é mais evidenciado nas cidades que possuem 
maior inserção do tráfico de drogas" (PORTELLA; ARAÚJO; OLIVEIRA; CHAVES; ROCHA; OLIVEIRA, 2019, p. 632).

Faria e Barros (2011) apontam que estes jovens são cada vez mais precocemente aliciados pela economia ilegal do tráfico de drogas a qual voluntariamente aderem em razão da escassez de opção de escolhas de outros modos de vida. Neste contexto, o tráfico se apresenta como um mercado extremamente lucrativo e com possibilidade de inserção para jovens moradores de áreas vulnerabilizadas pela degradação das formas de trabalho e ausência de políticas públicas (SCHERER; NUNES, 2018).

Se, por um lado, o tráfico de drogas se apresenta para muitos jovens como uma fonte lucrativa de renda e de inserção no processo de produção e consumo da lógica do capital (para atender aos apelos consumistas altamente incitados pelas ideias neoliberais contemporâneas), por outro, se estrutura em uma dinâmica violenta e criminal, articulada à rede de crime organizado, com disputa de poder entre grupos rivais do tráfico. Essa dinâmica compõe parte da realidade homicida de jovens no Brasil, haja vista que o preço da inclusão promovida pelo narcotráfico é alto, sendo em muitos casos a própria vida.

Outro importante agente homicida de jovens é o Estado. As políticas de repressão e combate ao narcotráfico por meio de ações de Segurança Pública têm resultado em verdadeiros conflitos bélicos resultando em um saldo significativo de mortos no qual se pode incluir, tanto pessoas ligadas ao tráfico, quanto moradores das áreas onde estes episódios acontecem e também policiais (SILVA; FERNANDES; BRAGA, 2008 apud SCHERER; NUNES, 2018).

Dentre as questões centrais que constituem o mercado ilegal de drogas e suas violências intrínsecas está a política de guerra às drogas adotada pelo Estado brasileiro em razão do paradigma proibicionista de homogeneidade internacional que conferiu, a partir da metade do último século, um caráter penal à questão. As leis de repressão às drogas acabam, inevitavelmente, aumentando a marginalização e a violência armada entre grupos rivais em suas disputas por mercado e com o próprio Estado nos confrontos policiais, o que culmina em altas taxas de homicídios. Deste modo, "A associação das políticas proibicionistas com o aumento da violência e da mortalidade por homicídio é provavelmente a consequência mais dramática da Guerra às Drogas" (GOMESMEDEIROS, FARIA, CAMPOS, TOFOLI, 2019, p. 5).

As ações bélicas de enfrentamento ao tráfico de drogas, amparadas em interesses econômicos e políticos e fundamentadas na lógica proibicionista, ocorrem travestidas de um discurso de combate ao narcotráfico em nome da manutenção da ordem e da segurança, resultando em violação de direitos de cidadania, criminalização da pobreza, barbárie e violência. Configuram-se não como ações de enfretamento à problemática das drogas, mas de combate à uma classe social (SCHERER, 2018b), com especificidade de raça/cor. A criminalização do jovem pobre, negro, morador das áreas de periferia dos centros urbanos se inscreve no quadro de desigualdade de morte violenta em jovens. 
Nesse contexto, a lógica proibicionista contribui para o processo de criminalização das drogas e para justificar o uso da força policial dirigidas àqueles considerados sujeitos perigosos, que devem ser combatidos violenta e criminalmente, na associação das medidas policiais e penais. No âmbito penal, Carvalho (2013) refere que "[...] O 'direito penal social' [...] pela sua espetacular manifestação como técnica de controle social punitivo, erige-se como instrumento para a legitimação moralizante da ordem social requerida pelo capitalismo organizado [...] (CARVALHO, 2013, p. 424).

Dados do Sistema Integrado de Informações Penitenciárias (InfoPen) sistematizados no ano de 2017 (até o mês de junho) mostram que, no Brasil, a distribuição numérica de pessoas em privação de liberdade quanto à cor de pele apresenta os seguintes números: $46,2 \%$ pardos; $35,4 \%$ brancos, $17,3 \%$ pretos. O somatório de pretos e pardos revela o índice de $63,5 \%$ das pessoas encarceradas. Já o recorte de faixa etária assinala que a maior parte é composta por jovens, sendo $29,9 \%$ entre 18 a 24 anos e $24,9 \%$ entre 25 a 29 anos, representando 54\% da população carcerária (BRASIL, 2019).

Longe das ruas, os que se encontram encarcerados, debaixo da tutela estatal, também não estão a salvo, tendo em vista que, só no ano de 2017, "Presídios localizados no Amazonas, Roraima, Rio Grande do Norte, Santa Catarina e São Paulo foram palcos de um massacre que resultou em 131 mortes, conseguindo ultrapassar até mesmo o número de mortos no massacre do Carandiru" (MENEZES NETO; BEZERRA, 2018, p. 474).

Mas, é preciso ressaltar que o grande promotor do juvenicídio vem a ser a dinâmica metabólica do capital, que segundo Scherer (2018b), diante da sua crise estrutural e em contexto de acentuação dos ideais neoliberais, promove um processo de aniquilação da vida dos jovens em função dos interesses de manutenção das taxas de apropriação de riqueza. Assim, o juvenicídio expõe a degradação social e comunitária gerada pelo processo de reprodução do capital, especialmente vivenciado na realidade brasileira atual, que produz um ciclo de exclusões e violação de direitos, tratando-se de uma lógica produzida e reproduzida pelo capitalismo moderno que descarta a vida daqueles que não se encaixam ao seu modo de produção, neste caso os jovens pobres e negros das áreas periféricas dos centros urbanos (SCHERER, 2018b).

Nesse contexto, a violação de direitos básicos reconhecidos pela Constituição brasileira como educação, habitação, saúde e o direito à vida com dignidade, na materialização da questão social, é sobreposta por uma violência letal, que delata por meio da morte de milhares de jovens todos os anos a gravidade e a crueldade produzida pelas desigualdades no país.

Ainda distantes de uma solução que trate plenamente a complexidade deste fenômeno, Santos, Oliveira, Paiva e Yamamoto (2012) sugerem além de políticas sociais, investimentos em pesquisas e intervenções que contribuam com o fornecimento de técnicas, instrumentos e subsídios para atuar em conformidade com os direitos humanos, na promoção da cidadania e protagonismo das categorias juvenis no enfrentamento às desigualdades. 


\section{Homicídios de jovens no Espírito Santo}

O homicídio de jovens na realidade capixaba vem se apresentado nas últimas décadas como um desdobramento da questão social manifesta no processo de urbanização experienciado pelo Espírito Santo a partir da década de 1970 para atender aos modos de produção capitalista que somente nesta época se apresentaram ao estado em sua versão industrial. O estado iniciou seu processo de industrialização nos anos de 1970, alavancada pela implantação de indústrias produtoras de bens de capital na Região Metropolitana da Grande Vitória (RMGV), instaurou um processo de urbanização que consequentemente atraiu milhares de pessoas para esta região (NADER, 2007).

Segundo Pochmann (2016), é possível classificar esse processo de industrialização como tardio, pois, nessa fase, a competição internacional capitalista era basicamente monopolista nas economias que exportavam produtos primários e tinha em seu passado o colonialismo, como no caso do Brasil. Esse padrão se delineou em razão das transformações que as estruturas e forças produtivas da nação vinham sofrendo sob o domínio do próprio capital industrial.

No cenário nacional, observava-se um crescimento econômico exponencial, entre os anos de 1968 a 1973 denominado de milagre econômico brasileiro, que impulsionou a industrialização em muitas cidades por meio de projetos como o II Plano de Desenvolvimento (II PND) que abrangeu o Espírito Santo (LIRA; MONTEIRO, 2017).

Em um contexto de industrialização, urbanização e migração, estabeleceu-se uma dinâmica espacial urbana de divisão de classes por territórios na RMGV que Harvey, citado em Scherer e Nunes (2018), denomina geografia capitalista, pois ao gosto do capital o espaço foi sendo transformado, com determinadas áreas sendo valorizadas em detrimento de outras. Consequentemente, problemas de natureza humana emergiram com esta fragmentação territorial, fruto de uma expansão desordenada e desarticulada de políticas sociais.

Os espaços desprezados eram justamente aqueles nas encostas de morros, nas áreas alagadas e nos manguezais, onde nem a infraestrutura urbana nem as políticas desenvolvimentistas alcançavam. Estes locais passaram a ser povoados pelos trabalhadores que não eram reabsorvidos pelas plantas industriais após a fase de construção (LIRA; MONTEIRO, 2017).

Como é típico no modo de produção capitalista, tão bem desvelado por Marx (1985), a lei geral da acumulação se impôs na RMGV, expandindo a força de trabalho disponível, pelos mesmos motivos que expandiu o capital, isto é, por meio do projeto de industrialização descolado do desenvolvimento social. Este movimento provocou inevitavelmente o que Marx denominou de exército industrial de reserva, pois o número de postos de trabalho reduziu, enquanto uma quantidade maciça de pessoas já estava estabelecida na região. E assim se configurou no estado um cenário de prevalência da questão social em razão dos desdobramentos sócio-políticos produzidos pelo aumento da massa urbana, do desemprego e da pobreza, indissociável ao desenvolvimento do capital (IANNI, 2002; NETTO, 2001). 
Tanto quanto o processo de industrialização, o enfrentamento dos problemas advindos ao contexto capixaba também se deu de modo tardio, o que somado a uma conjuntura de crise fragilizou ainda mais o tecido social em formação. Segundo Lira e Monteiro (2017) a ausência de políticas sociais ocasionou problemas socioeconômicos graves como a irregular ocupação do solo, desemprego, precariedade de serviços básicos, entre outros. Deste modo, foi possível notar rapidamente o crescimento da violência urbana, aqui entendida como uma expressão da questão social.

Deste modo, a partir de 1980 um crescente no número de homicídios já era observado e amplamente divulgado pela mídia local. Este padrão se consolidou da década seguinte, atravessou a virada do século e colocou o Espírito Santo por quase vinte anos nas primeiras posições dos rankings anuais de homicídios dos estados da nação evidenciando, claramente, a instalação do modelo de sociabilidade violenta resultante da fragmentação no tecido social.

As principais vítimas deste fenômeno disseminado foram os jovens. Um dos fatores que contribuiu para isso foi o fato de que, segundo Lira (2017) a população entre 15 e 24 anos da RMGV na década de 1980 era formada por jovens que migraram para esta região atraídos pelas possibilidades de trabalho e melhores condições de vida.

A população jovem foi a mais impactada pelos desdobramentos socioeconômicos do crescimento urbano desigual e consequentemente a mais vitimada pela violência letal, não apenas nos primeiros anos de sua manifestação, mas nos anos que se seguiram, confirmando assim a vulnerabilidade desta faixa etária aos fatores de risco de morte por homicídio, descrita por Routti, Massa e Peres (2011).

Para Zonatelli, Bertolde, Barros, Lira, Dalmasco e Bergamschi (2007), constata-se nos maiores municípios do Espírito Santo uma associação entre a concentração de riquezas e de pessoas e a ocorrência de crimes por conta do consumo e do tráfico de drogas. Logo, semelhante ao que é visto na totalidade da realidade brasileira, as atividades ilegais, sobretudo, as ligadas ao tráfico no estado se tornam uma opção "[...] à medida que os sujeitos não são preparados para o mercado de trabalho legal, cada vez mais competitivo e excludente" (FARIA; BARROS, 2011, p. 537).

Esse contexto de disseminação de atividades ilegais, vistas como alternativa para tentar driblar as condições de privação e descaso em que se encontravam muitos destes jovens, decorre do descarte de parte da mão de obra jovem, depois de ser usada para formar as bases do capitalismo industrial no estado nas décadas de 1970 e 1980. Fato que revela uma completa inexistência de políticas sociais voltadas para a proteção e amparo das juventudes na época de implantação das indústrias e também no período posterior.

Embora o século XX tenha inaugurado um novo momento para as juventudes, principalmente as dos países economicamente desenvolvidos, no Brasil, até a década de 1990, pouco ou nenhum reconhecimento se dava a esse segmento social, inclusive no contexto capixaba. Logo, não surpreende o fato de que em um cenário de desproteção provocado pela falta de reconhecimento de direitos em quase todos os aspectos, a 
emergência deste segmento se deu por meio de sua maciça participação nos registros de homicídios.

As décadas finais do século XX revelam um aumento sistêmico dos homicídios em todo o território nacional, como aponta Lira (2017), mas, no Espírito Santo, este aumento foi superior às médias nacionais, caracterizando um processo endêmico sobre o qual poucas ações de enfrentamento foram vistas por parte do poder público e da sociedade.

Considerando a taxa de homicídio na população total por 100 mil habitantes, em 1998 o estado esteve no segundo lugar com um marco de 58,4 mortes, em 2002 este quantitativo diminuiu para 51,2 o que deu ao estado a terceira posição no ranking. No ano de 2008 alcançou novamente a segunda posição com 56,4 que se repetiu em 2012 com uma taxa um pouco menor de 47,3 (WAISELFISZ, 2014).

Em relação aos homicídios de jovens, o estado possui um histórico de décadas de aniquilamento de suas juventudes. Isto é mostrado em estudos como os de Waiselfsz (2004), onde se destaca no ano de 2002 a mais expressiva e lamentável taxa, até então observada, de 103,7 mortes de jovens entre 15 e 24 anos para cada 100 mil habitantes. Porém, esta tendência homicida evidenciada em elevados índices permaneceu nos anos seguintes chegando a atingir um marco de 116,9 por 100 mil em 2009. E, embora se verifique uma tendência decrescente em 2012 e 2013, os números ainda se mostram bem elevados em relação à tendência brasileira, conforme pode ser visto na Figura 1 a seguir.

Figura 1 - Taxa de Homicídios de Jovens no Brasil e no Espírito Santo - 2003 A 2013

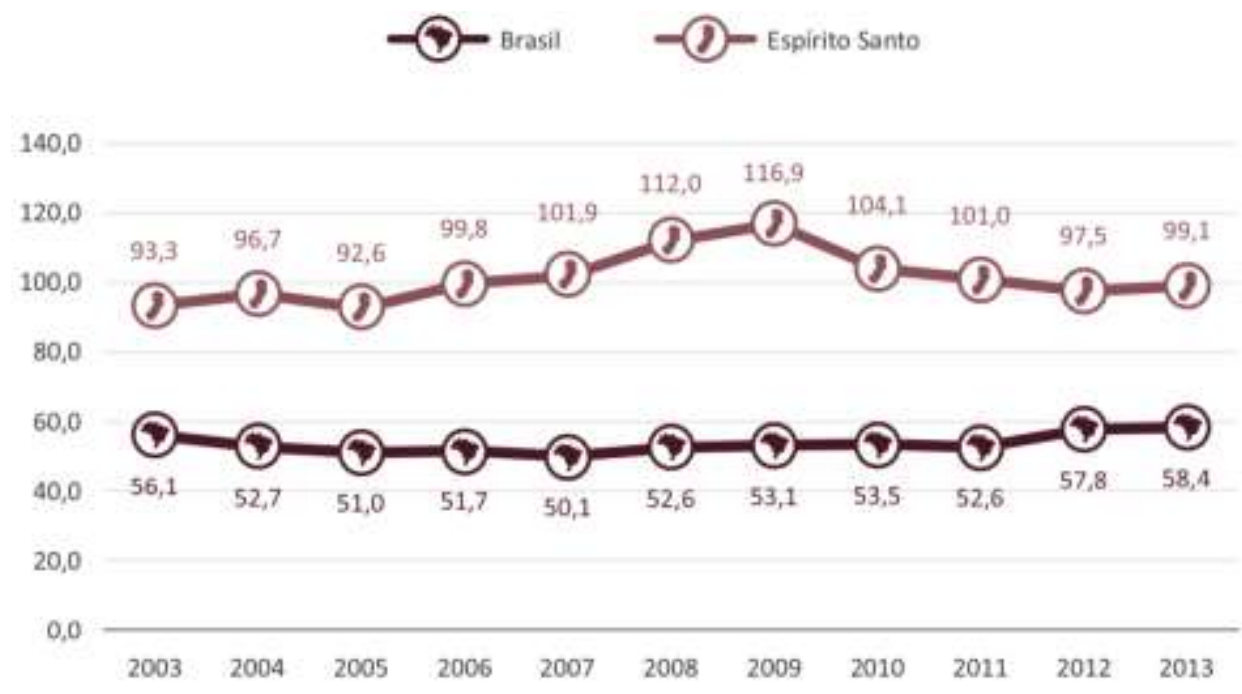

Fonte: Instituto Jones dos Santos Neves (2015, p. 23).

Segundo dados do IPEA (2018), nos anos de 2014, 2015 e 2016 a taxa de homicídios de jovens por 100 mil habitantes no estado foi de 97, 84 e 71,5 respectivamente. Porém, em 2017 quando ocorreu a greve da polícia militar, contrariando as baixas observadas nos anos anteriores, o índice voltou a subir correspondendo a 86,o, sendo que no Brasil, a taxa foi de 69,9 (INSTITUTO DE PESQUISA ECONÔMICA APLICADA, 2019), persistindo, assim, a tendência elevada em relação à taxa do País (que também é considerada alta). 
No que se refere ao gênero, pode ser observada uma predominância absoluta do sexo masculino dentre as vítimas. Dados mais recentes divulgados pelo IJSN (2019) apontam que em 2018 dentre aqueles que foram assassinados no estado 91,5\% eram do sexo masculino. Este indicativo coincide com as médias nacionais em que este percentual é de 91,8\%, segundo levantamento feito pelo IPEA (2019) entre os anos de 2007 e 2017.

No panorama geral de homicídios, além da predominância de gênero também é possível observar que alguns territórios do estado se sobressaem comportando uma maior quantidade de ocorrências. A RMGV, somente no ano de 2018 , foi responsável por 55,8\% do total geral de mortes deste tipo, seguida pela microrregião do Rio Doce e Nordeste, como $11 \%$ e $10 \%$ cada uma (INSTITUO JONES DOS SANTOS NEVES, 2019). As demais regiões tiveram um percentual menos expressivo.

São violências que se atrelam ao fato de que a composição populacional é cada vez mais urbana. Neste contexto, Scherer, Dilligenti e Araújo (2018), referem que as trajetórias de vida das juventudes nos espaços urbanos, em especial dos jovens moradores das áreas precarizadas, se mostram repletas de violações de direitos a que estão submetidos, inscritas no processo de juvenicídio e urbicídio.

Para Lira e Monteiro (2017) a distribuição espacial dos homicídios no território capixaba está diretamente relacionada às desigualdades socioeconômicas, segregações sócio espaciais e atividades do tráfico desencadeadas durante a trajetória de urbanização e industrialização, que se concentrou na RMGV.

Outro fator importante diz respeito a raça/cor das vítimas. Conforme informa o IJSN (2015), “[...] no estado do Espírito Santo, 80,8\% das vítimas dos homicídios foram declaradas negras (vítimas pretas e pardas) [...]" (INSTITUTO JONES DOS SANTOS NEVES, 2015, p. 28), configurando assim o que Scherer e Nunes (2018) afirmam sobre a dinâmica homicida do caso brasileiro que atinge especificamente jovens, pobres e negros. Revela-se, pois, como uma forma de genocídio da juventude negra das periferias urbanas.

A forma como essas mortes acontecem se assemelha ao que pode ser visto em todo o território nacional, isto é, por meio do uso de armas de fogo. Estas, foram usadas em $81,2 \%$ de todos os assassinatos cometidos no estado no ano de 2013. No ano seguinte, 2014, das 952 mortes de jovens registradas, 838 ocorreram em razão de perfurações causadas por projéteis disparados por armas de fogo, o que equivale a $88 \%$ delas, segundo dados do IJSN (2015) e IPEA (2016). Logo, a questão da política do (des)armamento precisa ser pensada levando em consideração os dados que comprovam sua ligação direta com os índices de homicídios de jovens tanto no estado, quanto no País.

Está evidenciado o perfil das principais vítimas de homicídios no Espírito Santo, qual seja; "[...] jovens de 15 a 29 anos, do sexo masculino, estado civil solteiro, com baixo nível de escolaridade e, potencialmente, assassinados por arma de fogo [...]" (INSTITUTO JONES DOS SANTOS NEVES, 2015, p. 31), negros, que residem majoritariamente em periferias urbanas. Este lastimável fenômeno se expressa de maneira intensa no caso 
capixaba, mas não representa uma particularidade de seu território, pois é visto em toda a totalidade da realidade brasileira e, por esta razão, sua análise não pode ocorrer de maneira descolada do contexto pátrio.

O fenômeno do juvenicídio, no caso do Espírito Santo, delineia-se da mesma maneira que na realidade brasileira, a partir da dinâmica destrutiva do capital em seu atual estágio de desenvolvimento. Apresenta-se como um processo cotidiano de destruição das juventudes por meio da precarização da vida dos jovens, ampliação de suas vulnerabilidades e diminuição de opções para o desenvolvimento dos seus projeto de vida, e toma curso sob a batuta aniquilante da política econômica neoliberal, que produz precarização do trabalho, marginalização, acentua desigualdades, reduz direitos, desmonta o Estado e as políticas públicas.

\section{Considerações finais}

A violência estrutural representa uma questão complexa mediada por diversos fatores, apresentando íntima relação com as condições estruturais do capitalismo em seu processo de organização e expansão e afeta de forma difusa a vida na sociedade, especialmente no que diz respeito às juventudes. $O$ capitalismo em sua atual configuração e sociabilidade opera para a produção de uma forma de manifestação da questão social que vem a ser o juvenicídio e a descartabilidade daqueles considerados indesejáveis pelo capital.

A ofensiva neoliberal que opera no sentido de reduzir os direitos sociais, precarizar o trabalho e as políticas públicas, tem aprofundado desigualdades e produzido inúmeras formas de violação de direitos, especialmente no que diz respeito ao processo de descarte, criminalização, marginalização, vulnerabilização econômica e social dos jovens, reduzindo as possibilidades e condições para que significativa parcela das juventudes possa levar adiante seus projetos de vida.

No Espírito Santo, o desenvolvimento urbano e suas complexidades inerentes tem comportado um ambiente de proeminentes contradições socioeconômicas traduzidas, por fim, em um alto número de homicídios, semelhante ao que pode ser visto na totalidade da realidade brasileira. Neste caso, o perfil das vítimas de homicídios se mostra semelhante ao nacional; jovens, do sexo masculino, negros, pobres, residentes em áreas periféricas dos centros urbanos, cuja morte se dá por meio do uso de arma de fogo. Verifica-se em curso no estado do Espírito Santo, tanto quanto na realidade brasileira, a desigualdade de morte violenta por raça/cor, que ratifica um processo de genocídio da juventude negra, produzido pelo entrelaçamento do racismo estrutural, da política de guerra às drogas e do Estado penal, coercitivo, punitivo e violento.

Apesar da série histórica de homicídio de jovens no Espírito Santo mostrar números decrescentes, ainda assim são índices altamente preocupantes, considerando a conjuntura atual de avanço do projeto econômico neoliberal em nosso país, que preconiza o baixo investimento em políticas sociais. A violência letal representada pelos homicídios de jovens, dentre outras expressões da questão social vivenciadas pelas juventudes na realidade brasileira e do estado do Espírito Santo, aponta para a real 
condição de desproteção social em que ainda se situam os jovens capixabas, radicada na dinâmica do capital em sua configuração atual, que erradica a vida de centenas de jovens todos os anos por meio de diversa formas de violência e violação de direitos.

O enfrentamento dessa realidade requer a articulação de ações de fortalecimento dos direitos sociais com a efetivação de políticas públicas firmadas na ética da proteção social como direito, na perspectiva da intersetorialidade e complementaridade das ações de educação, assistência social, saúde, cultura entre outras, fundamentais para o enfrentamento da violência cotidiana que as juventudes vivenciam. Mais do que nunca, exige uma compreensão da dinâmica atual do capitalismo para que se possa buscar a construção de estratégias de enfrentamento ao padrão civilizatório destrutivo do capital.

\section{Referências}

BARROS, J.P.P.; BENICIO, L.F.S.; SILVA, D.B.; LEONARDO, C.S.; TORRES, F.J.P. Homicídios Juvenis e os Desafios à Democracia Brasileira: Implicações Ético-políticas da Psicologia. Psicol. Cienc. Prof., Brasília (DF), v. 37, n. 4, p. 1051-1065, dez. 2017.

BRASIL. Lei no 12.852 de 5 de agosto de 2013. Estatuto da Juventude. Brasília (DF), 2013. Disponível em: http://www.planalto.gov.br/ccivil_03/_ato20112014/2013/lei/l12852.htm. Acesso em: 11 jun. 2019.

BRASIL. Ministério da Justiça e Segurança Pública, Departamento Penitenciário Nacional. Levantamento nacional de informações penitenciárias: atualização junho de 2017. Brasília (DF), 2019.

CARA, D.; GAUTO, M. Juventude: percepções e exposição a violência. In: ABRAMOVAY, M.; ANDRADE, E.R.; ESTEVES, L.C.G. (Org). Juventudes: outros olhares sobre a diversidade. Brasília (DF): Ministério da Educação, Secretaria de Educação Continuada, Alfabetização e Diversidade; Unesco, 2007. p. 171-196.

CARVALHO, Thiago Fabres de. O imaginário punitivo na aventuras de modernidade: a genealogia do pensamento criminológico entre regulação (poder sobreano) e emancipação (vida digna). Revista da AJURIS, Porto Alegre, v. 40, n. 130, p. 395-428, jun./2013.

COSTA, D.H.; SCHENKER, M.; NJAINE, K.; SOUZA, E.R. Homicídios de jovens: os impactos da perda em famílias de vítimas. Physis, Rio de Janeiro, v. 27, n. 3, p. 685-705, jul. 2017.

COSTA, M.R. A violência urbana é particularidade da sociedade brasileira? São Paulo em Perspectiva, São Paulo, v. 13, n. 4, p. 3-12, out./dez. 1999.

ESTEVES, L.C.G.; ABRAMOVAY, M. Juventude, Juventudes: pelos outros e por elas mesmas. In: ABRAMOVAY, M.; ANDRADE, E. R.; ESTEVES, L. C. G. (Org.).

Juventudes: outros olhares sobre a diversidade. Brasília: Ministério da Educação,

Argum., Vitória, v. 12, n. 1, p. 82-101, jan./abr. 2020. | ISSN 2176-9575 
Secretaria de Educação Continuada, Alfabetização e Diversidade; Unesco, 2007. p. 1954 .

FARIA, A.A.C.; BARROS, V.A. Tráfico de drogas: uma opção entre escolhas escassas. Psicol. Soc., Florianópolis, v. 23, n. 3, p. 536-544, dez. 2011.

FRANÇA, M.A. Sociabilidade violenta como modo de orientação da conduta:

Entendendo a especificidade da violência urbana brasileira contemporânea. DILEMAS:

Revista de Estudos de Conflito e Controle Social, Rio de Janeiro, v. 12, n. 1, p. 93123, jan./abr. 2019.

FREITAS, M.V. (Org.). Juventude e adolescência no Brasil: referências conceituais. São Paulo: Ação Educativa, 2005.

FREITAS, N.A.; SILVA, A.V.S.; BRASIL, A.C.O.; BASTOS, V.P.; FERNANDES, L.C.B.C. Perfil clínico-epidemiológico de adolescentes e jovens vítimas de ferimento por arma de fogo. Cadernos Saúde Coletiva. Rio de Janeiro, v. 25, n. 4, p. 429-435, jan./out. 2017 .

GOMES-MEDEIROS, D.; FARIA, P. H. de; CAMPOS, G. W. de S.; TOFOLI, L. F. Política de drogas e Saúde Coletiva: diálogos necessários. Cadernos de Saúde Pública, São Paulo, v. 35, n. 7, 2019.

IANNI, O. Raízes da violência. In: CAMACHO, T. (Org.) Ensaios sobre violência. Vitória: EDUFES, 2003.

IANNI, O. Violência na sociedade contemporânea. Estudos de Sociologia, Araraquara, n.12, p. 7-28, 2002.

INSTITUTO BRASILEIRO DE GEOGRAFIA E ESTATÍSTICA (IBGE). Tábua completa de mortalidade para o Brasil - 2017: breve análise da evolução da mortalidade no Brasil. Rio de Janeiro: IBGE, 2018.

INSTITUTO JONES DOS SANTOS NEVES. Boletim n. 24: Informações criminais do

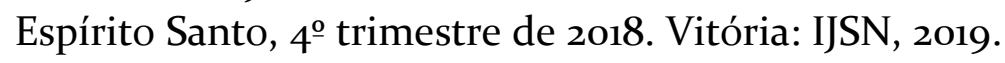

INSTITUTO JONES DOS SANTOS NEVES. Juventude e violência: uma análise comparativa dos homicídios no Estado do Espírito Santo. Vitória, ES, 2015.

INSTITUTO DE PESQUISA ECONÔMICA APLICADA. Atlas da Violência 2019. Brasília(DF) , 2019.

INSTITUTO DE PESQUISA ECONÔMICA APLICADA. Atlas da Violência 2018. Brasília (DF), 2018.

INSTITUTO DE PESQUISA ECONÔMICA APLICADA. Atlas da Violência 2o17. Rio de Janeiro, 2017. 
INSTITUTO DE PESQUISA ECONÔMICA APLICADA. Atlas da Violência 2016. Brasília, 2016.

LIRA, P.S. Geografia do crime e arquitetura do medo: uma análise dialética da criminalidade violenta e das instâncias urbanas. 2. ed. Rio de Janeiro: Letra Capital: Observatório das Metrópoles, 2017.

LIRA, P.S.; MONTEIRO, L.L. Violência, urbanização e desenvolvimento humano: uma análise espacial nos munícipios capixabas. In: MARGUTI, B.O.; COSTA M.A.; PINTO, C.V.S. (Org.). Territórios em números: insumos para políticas públicas a partir da análise do IDHM e do IVS de municípios e Unidades da Federação brasileira. Brasília (DF): Instituto de Pesquisa Econômica Aplicada, 2017. p. 243-270.

MARINI, R.M. Dialética da dependência: uma antologia da obra de Ruy Mauro Marini. Petrópolis: Vozes, 2000.

MARX, K. O Capital. Crítica da Economia Política. São Paulo: Nova Cultural, 1985.

MELO, A.C.M.; SILVA, G.D.M.; GARCIA, L.P. Mortalidade de homens jovens por agressões no Brasil, 2010-2014: estudo ecológico. Cad. Saúde Pública, Rio de Janeiro, v. 33, n. 11, p. 2-15, dez. 2017.

MENEZES NETO, E.J.; BEZERRA, T.J.S.L. A prática da mistanásia nas prisões femininas brasileiras ante à omissão do direito à saúde e a negação da dignidade humana. Rev. Bras. Polít. Públicas, Brasília (DF), v. 8, n. 1, p. 472-493, 2018.

NADER, M.B. Industrialização, aumento populacional e a diversificação do mercado de trabalho: Vitória em dados. 1970-200o. Revista História Hoje, São Paulo, v. 4, n. 12, abr. 2007.

NETTO, J. P. Capitalismo e barbárie contemporânea. Argumentum, Vitória, v. 4, n. 1, p. 202-222, jan./jun. 2012.

NETTO, J. P. Cinco notas sobre questão social. Temporalis, Brasília (DF): Associação Brasileira de Ensino e Pesquisa em Serviço Social, n. 3, p.41-5o, 2001.

OLIVEN, R.G. Violência e cultura no Brasil [online]. Rio de Janeiro: Centro Edelstein de Pesquisa Social, 2010, 94p. Disponível em: http://books.scielo.org. Acesso em: 14 maio. 2019.

POCHMANN, M. Capitalismo e desenvolvimento. In: Brasil sem industrialização: a herança renunciada. Ponta Grossa: Editora UEPG, p. 16-64, 2016.

PORTELLA, D.D.A.; ARAUJO, E.M.; OLIVEIRA, N.F.; CHAVES, J.M.; ROCHA, W.J.S.F.; OLIVEIRA, D.D. Homicídios dolosos, tráfico de drogas e indicadores sociais em Salvador, Bahia, Brasil. Ciência \& Saúde Coletiva, Rio de Janeiro, v. 24, n. 2, p. 631639, 2019. 
PRATES, J.C. A pesquisa social a partir do paradigma dialético-crítico: do projeto à análise do dado. In: FERNANDES, I.; PRATES, J.C. (Orgs.). Diversidade e estética em Marx e Engels. Campinas-SP: Papel Social, p. 105-137, 2016.

RODRIGUES, A. Violência e segurança pública no Brasil: algumas questões para uma agenda de debate e intervenção. In: NASCIMENTO, Fátima (Org.). (In)segurança pública e violência urbana: desafios e perspectivas. Salvador: Pão para o Mundo, p. 13-21, 2014.

ROUTTI, C.; MASSA, V.C.; PERES, M.F.T. Vulnerabilidade e violência: uma nova concepção de risco para o estudo dos homicídios de jovens. Interface - Comunic., Saúde, Educ., v. 15, n. 37, p. 377-89, abr./jun. 2011.

RUGGIERI NETO, M.T. Juventude e sociedade: fundamentos sociológicos para uma análise das políticas públicas para Juventude no brasil atual. ORG \& DEMO, Marília, v. 13, n. 2, jul./dez., p. 119-132, 2012.

SANTOS, L.I.C.; OLIVEIRA, A.M.; PAIVA, I.L.; YAMAMOTO, O.H. Juventude e violência: trajetórias de vida e políticas públicas. Estud. Pesqui. Psicol., Rio de Janeiro, v. 12, n. 2, p. 521-538, ago. 2012.

SCHERER, G.A. As juventudes diante da crise estrutural do capital: reflexões sobre a atual conjuntura brasileira. In: GROSSI, P. K. et al., Juventudes, violências, e políticas públicas. Porto Alegre: EDIPUCRS, p. 49-68, 2018a.

SCHERER, G.A. Territórios Violentados e Vidas Descartáveis: a dinâmica espacial do capital diante da crise estrutural. Emancipação, Ponta Grossa, v. 18, n. 2, p. 251-265, 2018b.

SCHERER, G.A. Juventudes e Políticas Públicas: reflexões quanto a garantia do direito às Seguranças. Revista Juventude e Políticas Públicas, v. 1, n. 1, dez. 2014.

SCHERER, G.A.; DILLIGENTI, M.P.; ARAUJO, R.S. Os dois lados da mesma moeda: urbicídio e juvenicídio na realidade brasileira. Iluminuras, Porto Alegre, v. 19, n. 47, p. 185-209, dez. 2018.

SCHERER, G.A.; GERSHENSON, B. Uma Promessa Civilizatória Perversa: as políticas públicas e juventudes na era neodesenvolvimentista. Textos \& Contextos, Porto Alegre, v. 15, n. 1, p. 160-170, jan./jul. 2016.

SCHERER, G.A.; NUNES, C.F. Juvenicídio: descartabilidade da vida humana no Brasil

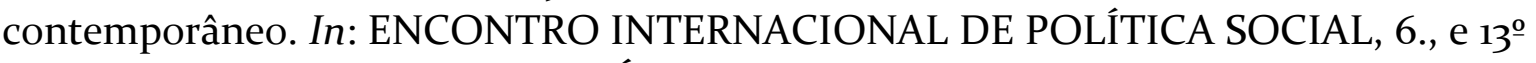
ENCONTRO NACIONAL DE POLÍTICA SOCIAL, 13., Vitória, 2018. Anais [...]. Vitória: Univesidade Federal do Espírito Santo, 2018.

SCHERER, G.A.; NUNES, C.F.; SANTOS, C.B. Violência estrutural e seletividade homicida das juventudes brasileiras na atual crise do capital. In: $5^{\mathbf{0}}$ ENCONTRO 
INTERNACIONAL DE POLÍTICA SOCIAL, 5., 2017, Vitória; ENCONTRO NACIONAL DE POLÍTICA SOCIAL, 12., 2017, Vitória. Anais [...]. Vitória: Univesidade Federal do Espírito Santo, 2017.

SILVA, C.R.S.; LOPES, R.E. Adolescência e Juventude: entre conceitos e políticas públicas. Cadernos de Terapia Ocupacional da UFSCar, São Carlos, v. 17, n. 2, p. 87106, jul./dez. 2009.

SILVA, J.F.S. Sociabilidade e violências: apontamentos críticos. In: GENTILLI, R.M.L.; COELHO, M.C.R. (Orgs.). Investigações sobre violência e sociabilidade: desafios transdisciplinares. São Paulo: Veras, 2015. p. 42-64.

VANLEZUELA, J.M. Juvenicidio: Ayotzinapa y las vidas precarias en América Latina y España. México: ITESO y El Colegio de la Frontera Norte, Biblioteca de la infancia y juventude, 2016.

WAISELFISZ, J.J. Mapa da Violência 2o14: os jovens do Brasil. Brasília: Secretaria Geral da Presidência da República, Secretaria Nacional de Juventude, Secretaria de Políticas de Promoção da Igualdade Racial, 2014.

WEYRAUCH, C. S. Violência Urbana. Dimensões, Vitória, v. 27, p. 2-22, 2011. Disponível em: www.periodicos.ufes.br/dimensoes/article/download/2580/2076. Acesso em: 20 out. 2019.

YAZBEK, M.C.; DEGENSZAJN, R.R.; PAZ, R.D.O. Desafios para o Serviço Social em tempo de avanços do conservadorismo. Serv. Soc. Soc., São Paulo, n. 134, p. 7-12, abr. 2019.

ZONATELLI, C.L.; BERTOLDE, A.I.; BARROS, A.M.L.; LIRA, P.S.; DALMASCO, R.; BERGAMSCHI, R.B. Geografia da criminalidade no Brasil: o caso do Espírito Santo. Vitória, 2007. Disponível em:

http://www.observatoriogeograficoamericalatina.org.mx/egalı/Geografiasocioeconomi ca/Geografiadelapoblacion/o5.pdf. Acesso em: 5 set. 2019.

Raysa Gloria dos Santos Raymundo CALAZANS. Trabalhou na realização da pesquisa e redação do texto.

Advogada. Mestre em Políticas Públicas e Desenvolvimento Local pela Escola Superior de Ciências da Santa Casa de Misericórdia de Vitória (EMESCAM). Atualmente sem vinculação institucional. Atua como Advogada autônoma.

Silvia Moreira TRUGILHO. Atuou no delineamento e elaboração do texto .

Assistente Social. Doutora em Educação pela Universidade Federal do Espírito Santo. Professora e pesquisadora em Curso de Graduação de Serviço Social e Pós-Graduação em Políticas Públicas e Desenvolvimento Local, em nível de Mestrado, da Escola Superior de Ciências da Santa Casa de Misericórdia de Vitória (EMESCAM). Possui experiência de atuação na área de Serviço Social e de políticas pública de saúde. Tem interesse no estudo de violência, direitos sociais, políticas públicas. 
Luciana Carrupt Machado SOGAME. Atuou na revisão crítica dos dados numéricos da pesquisa. Fisioterapeuta. Doutora em Ciências da Saúde pela Universidade Federal de São Paulo. Atua como docente e pesquisadora em Curso de Graduação de Fisioterapia e Medicina e Pós-Graduação em Políticas Públicas e Desenvolvimento Local, Mestrado, da Escola Superior de Ciências da Santa Casa de Misericórdia de Vitória (EMESCAM). Tem experiência na área de saúde coletiva, com ênfase em política de saúde, discutindo ciclo de vida, cuidado interdisciplinar e urgência e emergência. 